\title{
Is Internet Reciprocal Teaching the Remedy for Saudi EFL Learners' Reading Difficulties During the Covid-19 Pandemic?
}

\author{
Nasser Alasmari \\ Department of English छ Translation, University of Jeddah, Jeddah, Saudi Arabia. \\ Email:nslasmari@uj.edu.sa Tel: 966535997202
}

\section{Abstract}

The aim of this study was to investigate the applicability of Internet Reciprocal Teaching (IRT) for remedial English reading instruction in the EFL context, specifically for the purpose of overcoming the reading difficulties encountered by low-achieving Saudi students majoring in English at the University of Jeddah. The treatment phase lasted three months and, due to the COVID-19 pandemic and the resulting shift to online teaching, the instruments used were an online pre- and post-test of reading comprehension, an IRT dialogue rubric downloaded on the Blackboard platform that is used for online teaching, as well as a phone interview conducted with randomly selected students from the sample. The findings indicated significant improvements in the reading comprehension of the Saudi learners participating this study, as reflected in the students' effective use of the different IRT strategies and the significant results of the post-test. However, despite the proved effectiveness of IRT in strengthening reading comprehension, some challenges were voiced by the participants. These include computer competency, familiarity with online courses and, most notably, their linguistic difficulties with English, which justified their resorting to their native language (Arabic) as one way of demonstrating their comprehension. Finally, the paper draws pedagogical implications from the research results.

Keywords: Reading proficiency, Low achievers, Reciprocal teaching (RT), Internet reciprocal teaching (IRT), Challenges, Covid-19.

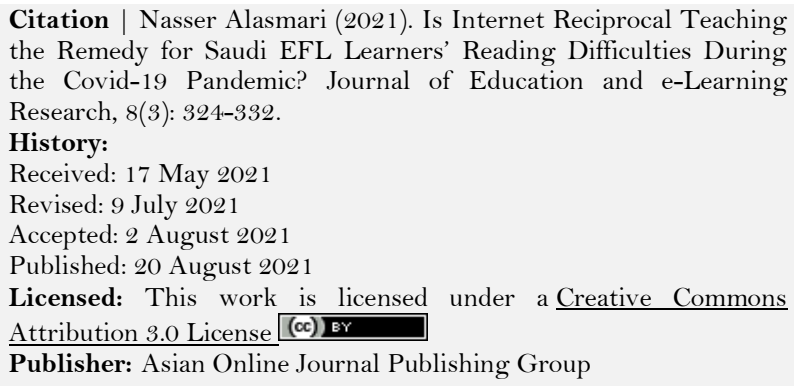

Citation | Nasser Alasmari (2021). Is Internet Reciprocal Teaching the Remedy for Saudi EFL Learners' Reading Difficulties During the Covid-19 Pandemic? Journal of Education and e-Learning Research, 8(3): 324-332. History:

Received: 17 May 2021

Revised: 9 July 2021

Accepted: 2 August 2021

Published: 20 August 2021

Licensed: This work is licensed under a Creative Commons

Attribution 3.0 License $(c)$

Publisher: Asian Online Journal Publishing Group

Funding: This study received no specific financial support

Competing Interests: The authors declare that they have no conflict of interests.

Transparency: The authors confirms that the manuscript is an honest, accurate, and transparent account of the study was reported; that no vital features of the study have been omitted; and that any discrepancies from the study as planned have been explained.

Ethical: This study follows all ethical practices during writing.

\section{Contents}

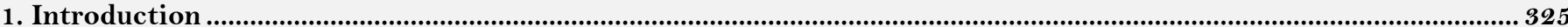

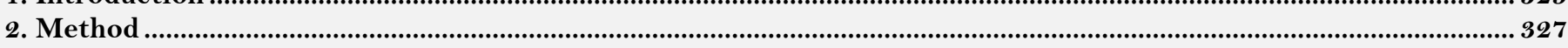

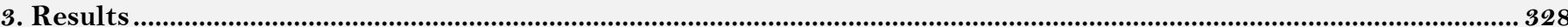

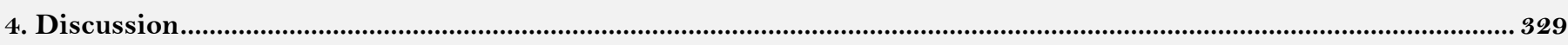

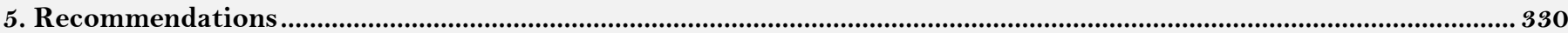

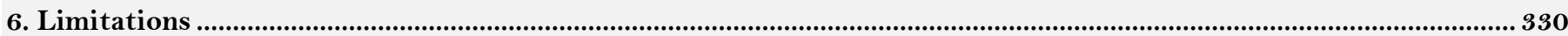

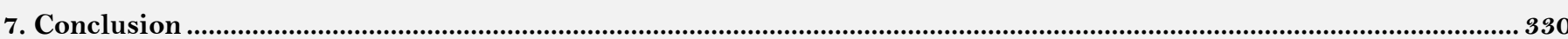

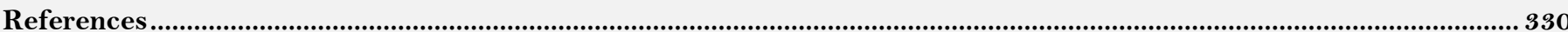

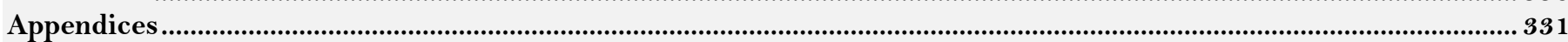




\section{Contribution of this paper to the literature}

This study draws on previous research on Internet Reciprocal Teaching (IRT) and demonstrates the effectiveness of IRT in boosting low-achieving Saudi learners' reading comprehension. The participants displayed advances in locating, evaluating and synthesizing information and communicating it to their peers. These results are a confirmation of previous research on the substantial contributions of the IRT instructional strategy to learners' reading and comprehension abilities.

\section{Introduction}

Reading is one of the skills most practiced in educational settings. Its importance, as maintained by Hung and Ngan (2015) stems from its crucial role in enhancing other aspects of learners' language acquisition, such as vocabulary, writing and speaking. Indeed, in the EFL context, reading helps learners to attain a high proficiency level in the target language and improves their language knowledge. Unfortunately, many teachers neglect, whether consciously or not, the difference between mere reading (fluency) and reading comprehension. In practical terms, it would be wrong to assume that fluent reading equals a solid understanding of what is read (O'Malley, 2017). The same author argues that reading simply means converting a given passage into sounds and spoken words, whereas comprehension is much deeper, as it reflects to what extent readers are able to construct meaning from the passage. Thus, the teaching of reading should necessarily be carried out synchronously with the teaching of comprehension. Indeed, pedagogists recommend that the teaching of reading should not be done in isolation of teaching comprehension skills. Learners, according to O'Malley (2017) can be seen as successful readers when they display the ability to identify written words as well as understand them. Researchers have explored the use of reading strategies as a possible way to help learners overcome reading difficulties. They claim that such strategies play a substantial role in enhancing readers' reading comprehension and boosting their language proficiency (Anderson, 2003; Cohen, 1998). Others have gone further and contend that the language proficiency of learners is strictly related to their use of reading strategies. Trehearne and Doctorow (2005) for instance, emphasize the usefulness of teaching comprehension methods and employing different reading comprehension strategies as key factors that significantly affect learners' reading comprehension. The question that arises in this respect is which instructional strategy would be able to improve readers' comprehension in the EFL context. This issue has become more critical due to the closure of educational settings forced by the Covid-19 pandemic, which has led to a switch to digital modes of learning as an alternative to conventional teaching. Accordingly, a more accurate version of the question would be: which online remedial English reading strategy could help improve the comprehension skills of EFL learners?

\subsection{Statement of the Problem}

In more specific terms, a review of the literature demonstrates the degree to which Saudi learners are struggling with the reading skill. It has been claimed that the reading level of Saudi test takers is the lowest worldwide, with reference to recent reports from IELTS 2012 and Educational Testing Services 2013 (Al-Qahtani, 2016). As such, finding the most suitable strategies for teaching reading becomes a necessity to help these learners overcome their difficulties and develop their reading skills. Reciprocal Teaching (RT) has been suggested as an effective way to promote reading comprehension (Yang, 2010). Further, and in the light of the unprecedented circumstances in which the use of distance learning is the only solution educationalists have been left with, Internet Reciprocal Teaching (IRT) has been introduced as an updated version of the recent instructional model of the conventional reciprocal teaching approach, which has proven its effectiveness in improving reading comprehension (Castek, Henry, Coiro, Leu, \& Hartman, 2015). According to these authors, IRT is a modified version of RT that supports online research and comprehension instruction and answers the present demands for online teaching forced by the school closures. The effectiveness of IRT in improving the reading comprehension of the Saudi learners majoring in English at the university of Jeddah serves as the focus of the current research.

\subsection{Significance of the Research}

This work draws upon the findings of a previous study carried out by the principal researcher in EFL classrooms (Alasmari \& Sultan, 2021). The author found that Saudi EFL learners struggle with various problems that hinder their reading comprehension and that can thus explain their poor reading level in particular and their lack of language proficiency in general. The current research examines the effectiveness of IRT as a possible remedy for these difficulties. It intends to measure how effective this instructional strategy is in promoting the reading comprehension abilities of the Saudi learners. Moreover, what drives this research is the shortage of literature available on remedial measures meant to improve the reading skills of EFL learners, despite the bulk of research available on reading difficulties and their causes. Another reason that motivates this research is the similarities of the challenges that EFL learners face in many different settings, which will ensure that the findings of this study and others on the same topic are applicable not only in the Saudi context but in other settings as well. This paper will contribute to the literature by providing an analysis of the different practical ways in which IRT can become an integral part of EFL teaching, with a particular focus on the challenges that may hinder its implementation. The paper is essentially meant to equip teachers and language instructors with a reflection on a practical experience that could help to shape their future teaching practices if IRT is to be adopted.

\subsection{Conceptualizing Reciprocal Teaching (RT) and Internet Reciprocal Teaching (IRT)}

Reciprocal teaching is a practical expression of Vygotsky's (1978) notion of the "proximal development zone" which reflects "the distance between the actual developmental level as determined by independent problem solving and the level of potential development as determined through problem solving under adult guidance, or in collaboration with more capable peers" (p. 86).

This kind of teaching has been conceptualized by Freihat and Al-Makhzoomi (2012) as a guided instructional activity that can be used during reading sessions and involves small groups of learners in which the students take turns to play the teacher and guide the dialogue about what has already been read. Nevertheless, the teacher still 
models in such groups and helps them to consciously and actively employ the following specific reading strategies: prediction, summarizing, generating questions and clarification. Part of this type of strategy is to involve both teachers and learners in conversation about segments of the passage with the aim of constructing meaning. In a similar vein, Hacker and Tenent (2002) stated that "reciprocal teaching is an instructional procedure in which small groups of students learn to improve their reading comprehension through scaffold instruction of comprehensionmonitoring strategies" (p.669). This scaffolding entails that the teacher or the more able learners help their less able counterparts successfully work through a given reading task. It is important to note, however, that the teacher's role gradually diminishes as the learners start to display command of the reading skills (Hou, 2015).

In broader terms, this method is based on the principles of active learning, which views learners as knowledge builders. They are at the heart of the learning process, as they seek to find meaning in their learning experiences. As such, learners become much more engaged in and responsible for their learning. This active learning, according to Chatmon, Chi, and Davis (2010), results in significant improvement in their retention of any of the language constructs in question.

IRT (internet reciprocal teaching), on the other hand, is an online version of reciprocal teaching that, according to Kuiper and Volman (2008), takes place though a complex process of enquiry and problem solving as readers try to find answers to questions through the use of the internet for the sake of comprehension and learning. In more specific terms, IRT is introduced as an alternative online model for teaching comprehension skills. It is a modified version of the reciprocal teaching instructional method and builds on the same principles of the latter model in that it revolves around the four main reading comprehension strategies, namely predicting, questioning, clarifying, and summarizing (Castek et al., 2015). The RT model is characterized by the gradual decrease of involvement of the teacher in the learning process. Likewise, the IRT model entails the release of responsibility to the learners.

\subsection{Internet Reciprocal Teaching (IRT) as a Three-Phase Model of Online Reading Instruction}

Given the experimental nature of the current work, an overview of the practical phases of this instructional method is of relevance.

The first phase of IRT is that of teacher-led instruction. As the name implies, the teacher is initially the one responsible for modelling online research and comprehension skills, leading group discussions, and giving thinkaloud demonstrations in the group.

The second phase is "the collaborative modelling of online research and comprehension strategies" (Leu, Zawilinski, Forzani, \& Timbrell, 2015). In this phase, the students take part in small group collaboration where they work on problem-based activities related to their curriculum standards which are meant to enhance their reading comprehension. Throughout this phase a gradual release of responsibility takes place, and the teacher moves from supplying more structure to less structure, as the learners begin to display signs of proficiency and advancement in online skills and strategies. In fact, a key element of this phase is the gradual progress towards the learners' independence as they start to engage in small groups in which they teach their classmates and teacher online reading and learning strategies.

The third and final stage is enquiry, in which the students display effective command of the use of such instructional strategies as searching for key words, effectively locating specific websites for pieces of information, critically evaluating them and synthesizing ideas from the information found. According to Block and Parris (2008), at this stage readers are expected to take the initiative to design their own research questions or solve a given problem. They play an active part in the learning process by communicating their findings to their classmates. This communication can take place using information and communication tools (ICT), such as emails and blogs, which, in turn, reflect and develop the learners' expertise in the use of technology.

\subsection{IRT and Reading Comprehension Improvement}

Some researchers, such as Yigiter, Saricoban, and Gurses (2005), have argued that the use of reading strategies is what differentiates good and poor readers. They outline the positive impacts of using reading strategies to make the reading experience a success. In addition, Pilonieta and Medina (2009) assert that proficient readers are those who make use of well-practiced triggering skills that help them achieve comprehension of a given passage. Lessable readers, on the other hand, usually lack such strategies and cannot feel the triggers that signal the breakdown of reading comprehension. Touching on this very issue, Mayer (1996) highlights reciprocal teaching as a method for helping learners to become more "adept" at employing reading strategies, thereby deepening their understanding of the text. With respect to the online version of RT, Leu and Reinking (2010) examined the effect of IRT on the reading comprehension of middle grade students, using a comparison between experimental and control groups. The authors conclude that the learners' reading comprehension in the experimental group increased considerably compared to the control group. Along the same lines, Huang and Yang (2015) investigated two different types of reading instruction that were suggested as remedies for the reading difficulties of 36 students. Their results indicate that the strategy of explicit teaching before reciprocal teaching (ET-RT) enhances the subjects' reading comprehension more than the strategy of direct instruction (DI), as the learners taught using the former method demonstrated higher levels of comprehension than those taught with the latter model, even though before the treatment phase their levels were equal.

Colwell, Hunt-Barron, and Reinking (2013), on the other hand, studied the effectiveness of the IRT model for increasing digital reading comprehension among students and found that open-ended inquiry projects are positively associated with the use of practice strategies, such as locating and critically evaluating information online. The authors add that the participants expressed a preference for using these strategies when working collaboratively rather than individually.

Although the literature suggests a number of promising positive impacts of IRT, its implementation poses a number of challenges that may detract from the potentially significant achievements.

\subsection{IRT Adaptation Challenges}

One drawback to reciprocal teaching, which also applies to IRT, has been raised by Allen (2003) and has to do with the discrepancy between the theory of the way in which this instructional method should be employed and the 
practice. In fact, constructivists encourage the prior introduction of the different strategies of the process to the students by an instructor who explicitly illustrates and models each of the strategies before the true implementation of reciprocal teaching, which is then mainly based on group discussions.

The linguistic level of the readers and their ability to decode a given passage is another significant but often overlooked challenge that may hinder the effective employment of reciprocal teaching. As argued by Le Fevre, Moore, and Wilkinson (2003), despite the immense potential of this method to enhance the learners' reading skills, it is not as effective for those who suffer from decoding problems. Similarly, Dennis (2008) reported that linguistic proficiency is a necessary prerequisite of the reading comprehension process. She adds that this process is very complex and ranges from the ability to identify printed symbols to the interpretation of these symbols' meaning. According to Le Fevre et al. (2003), learners with linguistic problems may be unable to break the words of the passage down into phonemes to pronounce them appropriately, which may cause embarrassment and feelings of discomfort before their peers in the group. Furthermore, Block and Parris (2008) emphasize assessment techniques as a challenge that teachers may encounter when employing IRT. They add that the online nature of this instructional method prevents traditional assessment techniques from being fully valid and reliable for tracking learners' progress in reading comprehension.

Another issue that may present a challenge to the educational implementation of this technique in the first place is the fact that collaboration is one of the key components of IRT. Students are expected to employ new technologies to solve problems from different perspectives through collaborative work. This is, in fact, a pressure that may affect the smooth cooperation between learners, especially those whose proficiency with technology is poor.

This study aims to investigate the effectiveness of IRT in enhancing the reading comprehension of Saudi low achieving learners majoring in English, and, to achieve this goal, is guided by the following research questions:

1. How effective is IRT in enhancing Saudi learners' reading comprehension skills?

2. What strategies are best/poorly practiced by the Saudi learners during the treatment phase?

3. What are the different benefits and challenges of the implementation of IRT, as perceived by the Saudi learners?

\section{Method}

\subsection{Subjects}

The participants in this study, which was conducted online via the Blackboard platform during the first term of the 2020-2021 academic year, are 60 Saudi EFL learners in the $4^{\text {th }}$ year of their Bachelor of Arts (BA) program at the University of Jeddah, Khulais branch. In fact, these participants are among the 72 students who contributed to a related study carried out by the principal author (Alasmari \& Sultan, 2021) in the previous term. This population has been classified as "low-achievers," due to their difficulties with the reading skill. They are all male students aged between 22 and 26. The participants were divided into experimental and control groups. All the relevant students $(\mathrm{N}=72)$ were sent emails briefing them about the aims and method of the research and requesting their participation, and 61 favorable answers were received. To ensure equal sizes of the experimental and control groups, 60 participants were selected.

Two language instructors agreed to contribute to this research and help the principal author, who implemented the IRT method during online classes with the experimental group. The first instructor, who had many years of experience teaching online courses, was responsible for observing the experimental group. He had attended training on the IRT method and its employment in educational settings and would attend the reading classes (as a second moderator, which is an option provided by Blackboard) throughout the treatment phase. The second instructor taught the control group and ensured their successful online completion of the pre- and post-test.

\subsection{Instruments}

Three instruments were used to collect data for this research, namely; a reading comprehension test (Appendix A), an IRT dialogue rubric (Appendix B); and a phone interview (Appendix C). The first instrument involved a reading passage from a magazine article about giving feedback at work, along with questions whose ultimate aim was to measure the participants' reading comprehension skills while employing IRT. This passage was obtained from the LearnEnglish (British Council) online library; it was selected based on a number of criteria, including length, complexity, authenticity, genre and assumed interest.

The second instrument was adapted from Castek et al. (2015) and was intended to document the students' progress in the use of the four reading strategies across the IRT sessions. This progress was assessed on a scale from 1 (beginning) to 4 (exemplary). The third instrument, the phone interview, consisted of 10 questions and was conducted with 20 randomly selected members of the experimental group. Its main purpose was to identify the benefits and challenges of IRT, as perceived by the Saudi learners.

\subsection{Procedure}

Given the experimental nature of the research, both the experimental and control groups took the test at the onset of the treatment phase (as a pre-test) in order to identify their proficiency level in reading comprehension and, in particular, to find out if they had any prior knowledge of IRT strategies. The same test was administered to the learners as a post-test at the end of the term (12 weeks after taking the pre-test) in order to measure the degree to which their reading comprehension had advanced through their use of the IRT strategies and techniques. The tests were administered online via Blackboard. At the end of the treatment phase, 20 randomly selected students from the experimental group participated in phone interviews with the principal researcher.

The first three sessions of the treatment phase served as a pilot study, with the aim of identifying any deficiency in the research design and introducing the learners to the IRT method to make sure they developed familiarity with it. This was meant to confer credibility and validity on the potential results of the experiment. Specifically, the pilot phase involved familiarizing the students with the four RT strategies - predicting, questioning, clarifying and summarizing - along with guided modeling on the part of the teacher, who 
progressively released responsibility to the students, gradually encouraging them to take turns to guide the group and apply the strategies. The fourth session was the start of the experimental phase, in which the students were randomly divided into groups of 5. The IRT instruction was based on a series of lessons which included (1) reading between a homepage and one linked webpage, (2) reading within multiple webpages bound to one website, (3) reading within a search engine, (4) reading the entire Web and, and (5) reading and writing online messages. All these lessons progressively helped learners to acquire and practice strategies such as inferencing, evaluating websites, inquiring about electronic resources, searching for specific and relevant information, and synthesizing information from multiple resources in order to construct clear messages and ideas that logically follow from the reading passages and contexts through summarizing and predicting.

For the statistical analysis of the data, descriptive statistics including mean, standard deviations and differences of means were computed for both the experimental and the control groups. To explore the significance of the difference between the mean scores of both groups on the pre-test and post-test, paired sample T-Tests were applied using the SPSS program (Statistical Package for Social Sciences), version 0.20, in which the level of significance was set at 0.05 . Student performance was assessed throughout each of the 9 sessions where the rubric was downloaded from Blackboard by the second moderator, whose job was to keenly observe the students' implementation of the strategies across their reading, who systematically scored each student on a range from 1 to 4 for each of the four strategies. The systematic scoring through close observation of the learners' performance using the IRT model helped the second moderator document the progress of the learners' reading abilities and thus generate a comprehensible account of the applicability of this method. Finally, the interview data were thematically analyzed after being recorded and transcribed. Only the recurring themes were approached inductively.

\section{Results}

Table-1. Comparison of pre-test results of control and experimental groups.

\begin{tabular}{l|l|c|c|c|c|c}
\hline \multirow{3}{*}{ Pre-test } & Group & N & Mean & Std. Deviation & t-value & p-value \\
\cline { 2 - 6 } & Control group & 30 & 72.1 & 1.62 & \multirow{2}{*}{$0.300^{*}$} & 0.834 \\
\cline { 2 - 5 } & Experimental group & 30 & 72.3 & 1.54 & & \\
\hline
\end{tabular}

Note: * Non-significant $(\mathrm{p}>0.05)$ table value of $\mathrm{t}$ at $0.05=2.017$.

Table 1 above displays a comparison between the pre-test results of the control and experimental groups. The former's mean score on the pre-test was 72.1, while the latter's was 72.3. The computed value of $t$ was 0.300 , which is statistically non-significant as it is less than the critical table value of $t$ at the level of 0.05 . The mean score values indicate that no significant difference in performance between the two groups, entailing that they had an equal proficiency level before the treatment phase.

Table-2. Comparison of post-test results of control and experimental groups.

\begin{tabular}{l|l|c|c|c|c|c}
\hline \multirow{3}{*}{ Post-test } & Group & $\mathbf{N}$ & Mean & Std. Deviation & T & P \\
\cline { 2 - 7 } & Control group & 30 & 68.7 & 1.57 & $3.35^{*}$ & \multirow{2}{*}{0.001} \\
\cline { 2 - 5 } & Experimental group & 30 & 92.2 & 1.32 & & \\
\hline \multirow{2}{*}{ Note: *Significant $(\mathrm{p}<0.05)$ table value of $\mathrm{t}$ at $0.05=2.017}$.
\end{tabular}

Table 2 shows that the control group's mean post-test score was 68.7, while the experimental group's reached 92.2. The computed value of t equaled 3.354, making the result statistically significant, as it is higher than the critical value of $t$ at the level of 0.05 . The results in this table demonstrate that the learners who took part in the experimental group outperformed their counterparts in the control group and achieved a significantly higher result on the post-test.

Table-3. Scoring of the learners' performance on the four IRT strategies.

\begin{tabular}{l|c|c|c|c|c|c}
\hline Strategy & $\mathbf{N}$ & Beginning (1) & Developing (2) & Accomplished (3) & Exemplary (4) & Overall Score \\
\hline Questioning & 30 & 27 & 72 & 189 & 576 & 96 \\
\hline Clarifying & 30 & 18 & 54 & 108 & 765 & 104 \\
\hline Summarizing & 30 & 54 & 198 & 162 & 252 & 74 \\
\hline Predicting & 30 & 81 & 162 & 162 & 216 & 69 \\
\hline
\end{tabular}

Table 3 presents the systematic scoring of the students' performance during the implementation of the IRT instruction. The total score for each of the four strategies in the session should ideally range from 90 to 120 , which would reflect a good performance in the subject, while a score of 60 or less indicates a poor performance in the subject. Indeed, the average response value for each strategy was calculated by adding the total number of responses in the subjects for each strategy throughout all the treatment sessions (9) and then multiplying it by the number of the statement on the scale (1, beginning; 2, developing; 3, accomplished; 4, exemplary;). As indicated, the responses across the scale do not show wide variations, and the average response value is near 3 or higher. This is indicative of an accomplished or exemplary performance. In the case of the questioning strategy, for instance, most of the learners demonstrate an exemplary performance (576) and to a lesser extent an accomplished one (189). The close observation of the learners shows a high performance in the use of the clarification strategy (104). However, scores were slightly lower as far as summarizing (74) and predicting (69) are concerned.

Table-4. Recurring themes in the phone interviews.

\begin{tabular}{ll|c|c}
\hline Themes & Number of learners & Frequency \\
\hline - & Technology proficiency & 18 & 33 \\
\hline - $\quad$ Linguistic difficulties & 19 & 43 \\
\hline - $\quad$ Lack of collaboration and cooperation & 13 & 18 \\
\hline
\end{tabular}


This paper broadly seeks to discover whether IRT is an effective strategy for overcoming reading difficulties. Table 4 above gives a part of the answer, as it displays the results obtained from the data collected through phone interviews. Only 20 of the 60 students who made up the total number of participants were randomly selected to be interviewed. Their responses concerning their perceptions of the challenges posed by the application of IRT were thematically interpreted and analyzed. The challenge most commonly mentioned by the informants was the required proficiency with technology (mentioned 55 times by 18 students), indicating that because they are not used to frequent computer use, it is a real challenge in their reading comprehension journey. The informants also expressed that their ignorance of the meanings of words (linguistic difficulties) hindered their comprehension of a reading passage. Another slightly less frequent problem, mentioned by 13 of the subjects, was a lack of cooperation among their peers on the one hand, and their teacher on the other.

\section{Discussion}

The main aim of this study was to investigate the effectiveness of integrating IRT as a teaching strategy to strengthen low-achieving learners' English reading comprehension. The results of the pre-test confirm the homogeneity of the experimental and control groups, in terms of their performance level. That is to say, the learners in the two groups share the same proficiency level in terms of reading comprehension at the beginning of the experiment. At the end of the experiment, however, a statistically significant difference is apparent between the two groups' performance on the post-test; the experimental group exhibited a better performance than the control group. This proves that the adoption of IRT helped to enhance the reading comprehension skill of the Saudi learners of English informing this research. The considerable improvement in reading comprehension displayed by the members of the experimental group is evidenced by the increase in their mean scores compared to the scores of the control group. In fact, these results are congruent with those of many other researchers who have confirmed the effectiveness of IRT in boosting the reading comprehension of learners. Tseng and Yeh (2018), for instance, asserted that the reading comprehension of low achievers improved after practicing RT in an online environment. Similarly, Ali (2017) reported that the subjects in the experimental group outperformed those in the control group in terms of reading comprehension and attributed this difference to the implementation of IRT strategies in the experimental group, thus concluding that IRT has positive effects on the development of learners' reading comprehension.

Simply put, the results gained from data analysis demonstrate that the experimental group, which was taught reading using the IRT method, was more successful on the post-test than the control group. The considerable reading comprehension improvements the former showed can be attributed to the employment of IRT strategies. This strongly supports the argument that integrating IRT boosts the reading comprehension of low-achieving learners.

As for the progress made by the students throughout the treatment phase, the IRT dialogue rubric downloaded on Blackboard reflected evident advances. In fact, most of the learners displayed exemplary performance in practicing these strategies and were observed to be skilled in generating questions and synthesizing information from one or more links to a website's content and combining them with their prior knowledge. They were also observed to use strategies for word clarification that can be applied generally across reading contexts and to successfully summarize text content. These results lend strong support to Tseng and Yeh (2018), who reported that the informants in their study excelled in using and practicing IRT strategies - mainly questioning and predicting. They came to the conclusion that the use of IRT strategies improved the reading comprehension level of low achievers. The same results were also found by Ali (2017), who reported the positive effects of employing RT strategies in teaching online reading to learners with low levels of proficiency.

The benefits of employing IRT were evident from the post-test results and the high IRT dialogue rubric scores the Saudi learners obtained. The data collected from the interview confirmed this, as the improvement in reading comprehension was highlighted as one of the benefits that the informants reaped during the treatment phase. Another important finding that emerges from this research is the effect of employing IRT on the students' motivation. The subjects' responses in the interview reflect a great sense of involvement and motivation to perform the assigned roles of a leader or teacher. This is in line with the findings of Pammu, Amir, and Maasum (2014), who argued that the use of RT helps learners gain confidence and competence in using reading comprehension strategies. In the same vein, the subjects appreciated the fact that they were more responsible for their learning and argued that despite their poor level, IRT gives them the opportunity to take charge of their learning and make them more responsible and thus autonomous. This result contradicts Farahani's (2014) conclusion that Saudi learners are reluctant to assume any responsibility for their learning.

In terms of the challenges of employing IRT, the informants identified a lack of proficiency with technology as a commonly recurring issue. Although the university students of today seem to be "savvy" about the use of technology, given that they are growing up in a "digital world", "technology phobia" is still a persistent issue that must be addressed. This hesitancy could be explained by the sudden move to remote learning caused by the pandemic and the unpreparedness of the Saudi learners to embrace this change and take online courses. In this respect, Coiro (2014) claimed that "most students greatly overestimated their ability to use digital technologies for academic learning purposes" (p.10). The participants also emphasized that they faced linguistic difficulties owing to their level of English and argued that they would have been able to assume more leading roles when applying this instructional method if their English level had been higher. They added that they at times resorted to their native language to express their ideas and show that they really understood the given passages and knew how to use the different strategies. Al-Rabai (2017) emphasized that the use of the Arabic language in EFL classrooms is a commonly known learning practice among Saudi learners and this goes towards explaining their low level of achievement in English.

Finally, the learners complained about a lack of cooperation among the group members and attributed this to the random division made at the beginning of the treatment phase. They added that if the reading tasks became an increasingly autonomous activity, it would be better to let them choose the group they wanted to belong to. This is strongly congruent with the findings of Jenkins (2010), who reported that a lack of cooperation among group members can negatively affect the implementation of IRT, leading to the reading difficulties not being addressed. 


\section{Recommendations}

In light of the preceding analysis and results of this research, the following recommendations are put forward:

The experimental group displayed excellent advancements in reading comprehension after applying the IRT method and outperformed the control group who were taught reading in the conventional way via the Blackboard platform. This lends strong support to the argument that IRT is an effective way to enhance the reading comprehension of low achieving learners. If this is the case, language instructors should be trained to successfully incorporate IRT in their teaching in EFL contexts. Even though online learning has had to be resorted to due to the COVID-19 pandemic, the online teaching of reading has proved to be a success in the Saudi setting, and teachers should thus be prepared to incorporate online strategies into their teaching under any circumstances. The Saudi learners seemingly preferred digital learning to conventional learning. Institutions and instructors should consider carrying out a needs analysis in order to identify the best teaching method to suit learners' preferences, especially since the mastery of technology and its incorporation in educational settings is one of the requirements of the $21^{\text {st }}$ century. This may necessitate the move of reading from the "page" or "print" to the "screen" (Leu, Forzani, \& Kennedy, 2015). The same point has previously been made by Rideout, Foehr, and Roberts (2010), who draw the attention of educationalists to the fact that the new media generations spend much more time reading on screens than they do on conventionally printed passages; therefore, a consideration of the gap between online and offline reading achievements becomes highly relevant. Because online information is becoming more and more important in our daily lives, the integration of online reading, which is mainly based on inquiry, in education and learning programs would be very helpful for learners as they advance through the educational systems. Moreover, one possible explanation for the progress made by the low-achieving learners in reading comprehension is the release of responsibility from the teacher to the learner, as dictated by the principles of RT. In effect, the learners felt more responsible for their learning and thus became more confident and self-efficacious, which, in turn, positively affected their reading comprehension skill. This suggests the hypothesis that the more autonomy learners enjoy in their learning, the more self-sufficient they feel and accordingly the better their achievements. Research that investigates such aspects is urgently needed in order to confirm or reject this hypothesis.

One further recommendation stems from the relatively low level of progress made by the Saudi learners in terms of the strategies of summarizing and predicting, as compared to questioning and clarifying. This may be explained by their low level of linguistic competence, which prevents them from clearly articulating or writing their summaries without resorting to their native language. Therefore, more attention needs to be paid to such handicaps, and remedial actions should be taken to improve the linguistic level of the students so that it can more clearly reflect their level of comprehension. The Saudi learners in this study understand the text but cannot express their ideas because they lack the vocabulary to help them display their comprehension.

\section{Limitations}

Despite its potential contribution to the literature on RT, and IRT in particular, the current study suffers from some limitations. One important point that prevents this research from being generalizable is the relatively limited number of informants $(\mathrm{N}=60)$. This number cannot be representative of all Saudi learners majoring in English. Also, these informants are all male students; insights from the experiences of female learners would have enriched the work and added value to it. Finally, language involves other constructs, such as listening, writing, and speaking which are not considered within the scope of the current study. Accordingly, the effectiveness of IRT on improving the other constructs should be investigated in future studies.

\section{Conclusion}

This study has demonstrated the effectiveness of IRT in boosting low-achieving Saudi learners' reading comprehension. Learners from the experimental group outperformed those from the control group in the post-test, although they shared the same reading comprehension level before the treatment phase. Indeed, the experimental group displayed advances in locating, evaluating and synthesizing information and communicating it to their peers. These results are a confirmation of previous research on the substantial contributions of the IRT instructional strategy to learners' reading and comprehension abilities. Thus, increased adoption and implementation of IRT in English reading classes should be considered, especially given the adjustments to teaching and the unexpected move to online education forced by the COVID-19 pandemic. Furthermore, the challenges identified by the Saudi learners during this research are not specifically related to the IRT method. They are broadly related to the inevitable process of presenting and running classes online. Even though these drawbacks are explainable and to a certain extent justifiable under the unprecedented circumstances the whole world is witnessing, much more scrutinized focus on remote teaching and learning, which has become trendy these days, is required from all the stakeholders in the field of education.

\section{References}

Al-Qahtani, A. A. (2016). Why do Saudi EFL readers exhibit poor reading abilities. English Language and Literature Studies, 6(1), 1-15. Available at: https://doi.org/10.5539/ells.v6n1p1.

Al-Rabai, F. (2017). Saudi EFL teachers' perspectives on learner autonomy. International Journal of Linguistics, 9(5), 211-231. Available at: https://doi.org/10.5296/ijl.v9i5.11918.

Alasmari, N., \& Sultan, N. Y. (2021). Reading difficulties and influential factors faced by Saudi tertiary learners. Asian ESP Journal, 17(1), 73100 .

Ali, A. D. (2017). The effects of internet reciprocal teaching on EFL students' new literacies of online comprehension and self-efficacy. Journal of Education and Scientific Research, 41(2), 57-94. Available at: https://doi.org/10.21608/jfees.2017.84150.

Allen, S. (2003). An analytic comparison of three models of reading strategy instruction. International Review of Applied Linguistics in Language Teaching, 41(4), 319-338. Available at: https://doi.org/10.1515/iral.2003.015.

Anderson, N. J. (2003). Scrolling, clicking and reading English: Online reading strategies in a second/ foreign language. The Reading Matrix, 3(3), 1-33.

Block, C. C., \& Parris, S. R. (2008). Comprehension instruction: Research-based best practices. Solving problems in the teaching of literacy. New York: Guilford Press. 
Castek, J., Henry, L., Coiro, J., Leu, D., \& Hartman, D. (2015). Research on instruction and assessment in the new literacies of online research and comprehension. In S. Parris and K. Headley, Comprehension Instruction: Research-Based Best Practices (3rd ed., pp. 324-344). NY: Guilford Press.

Chatmon, C., Chi, H., \& Davis, W. (2010). Active learning approaches to teaching information assurance. Paper presented at the Information Security Curriculum Development Conference 2010, October 1-3, 2010, Kennesaw, GA, USA.

Cohen, A. D. (1998). Strategies in learning and using a second language. New York: Longman.

Coiro, J. (2014). Online reading comprehension: Challenges and opportunities. Paper presented at the Annual Meeting of the XI Virtual Meeting of Documentation in Free Software (EVIDOSOL) and VIII International Congress of Language and Technology online (CILTEConline).

Colwell, J., Hunt-Barron, S., \& Reinking, D. (2013). Obstacles to developing digital literacy on the Internet in middle school science instruction. Journal of Literacy Research, 45(3), 295-324. Available at: https://doi.org/10.1177/1086296x 13493273.

Dennis, D. V. (2008). Are assessment data really driving middle school reading instruction? What we can learn from one student's experience. Journal of Adolescent \& Adult Literacy, 51(7), 578-587. Available at: https://doi.org/10.1598/jaal.5 1.7.5.

Farahani, M. (2014). From spoon feeding to self-feeding: Are Iranian EFL learners ready to take charge of their own learning? Electronic Journal of Foreign Language Teaching, $11(1), 98-115$.

Freihat, S., \& Al-Makhzoomi, K. (2012). The effect of the reciprocal teaching procedure (RTP) on enhancing EFL students' reading comprehension behavior in a university setting. International Journal of Humanities and Social Science, 2(5), 279-291.

Hacker, D. J., \& Tenent, A. (2002). Implementing reciprocal teaching in the classroom: Overcoming obstacles and making modifications. Journal of Educational Psychology, 94(4), 699-718. Available at: https://doi.org/10.1037/0022-0663.94.4.699.

Hou, Y.-J. (2015). Reciprocal teaching, metacognitive awareness, and academic performance in Taiwanese junior college students. International Journal of Teaching and Education, 3(4), 15-32. Available at: https://doi.org/10.20472/te.2015.3.4.003.

Huang, C.-T., \& Yang, S. C. (2015). Effects of online reciprocal teaching on reading strategies, comprehension, self-efficacy, and motivation. Journal of Educational Computing Research, 52(3), 381-407. Available at: https://doi.org/10.1177/0735633115571924.

Hung, D., \& Ngan, V. P. T. (2015). Investigating reading strategies used by EFL students at Dong Thap University. Asian Journal of Educational Research, 3(4), 10-20.

Jenkins, H. (2010). Confronting the challenges of participatory culture: Media Education for the 21st Century. McArthur Foundation. Cambridge: The MIT Press.

Kuiper, E., \& Volman, M. (2008). The web as a source of information for students in K-12 education. In J. Coiro, M. Knobel, C. Lankshear, \& D. Leu (Eds.), Handbook of research on new literacies (pp. 241-246). Mahwah, NJ: Erlbaum.

Le Fevre, D. M., Moore, D. W., \& Wilkinson, I. A. (2003). Tape-assisted reciprocal teaching: Cognitive bootstrapping for poor decoders. British Journal of Educational Psychology, 73(1), 37-58. Available at: https://doi.org/10.1348/000709903762869905.

Leu, D. J., Zawilinski, L., Forzani, E., \& Timbrell, N. (2015). Best practices in teaching the new literacies of online research and comprehension. Retrieved from https:// www.researchgate.net/publication/237579320.

Leu, D. J., \& Reinking, D. (2010). Developing Internet comprehension strategies among adolescent students at risk to become dropouts. U.S. Department of Education, Institute of Education Sciences Research Grant. Retrieved from: www.newliteracies.uconn.edu/iesproject/researchdocuments.html.

Leu, D. J., Forzani, E., \& Kennedy, C. (2015). Income inequality and the online reading gap: Teaching our way to success with online research and comprehension. The Reading Teacher, 68(6), 422-427. Available at: https://doi.org/10.1002/trtr.1328.

Mayer, R. E. (1996). Learning strategies for making sense out of expository text: The SOI model for guiding three cognitive processes in knowledge construction. Educational Psychology Review, 8(4), 357-371. Available at: https://doi.org/10.1007/bfo1463939.

O'Malley, N. (2017). Reciprocal teaching: Improving students reading comprehension. Master Thesis. Hamline University St. Paul, Minnesota.

Pammu, A., Amir, Z., \& Maasum, T. N. R. T. M. (2014). Metacognitive reading strategies of less proficient tertiary learners: A case study of EFL learners at a public university in Makassar, Indonesia. Procedia-Social and Behavioral Sciences, 118, 357-364. Available at: https://doi.org/10.1016/j.sbspro.2014.02.049.

Pilonieta, P., \& Medina, A. L. (2009). Reciprocal teaching for the primary grades:"We can do it, too!”. The Reading Teacher, 63(2), 120-129. Available at: https://doi.org/10.1598/rt.63.2.3.

Rideout, V. J., Foehr, U. G., \& Roberts, D. F. (2010). Generation M2: Media in the lives of 8-18-year-olds. Menlo Park, CA: Henry J. Kaiser Family Foundation.

Trehearne, M. P., \& Doctorow, R. (2005). Reading comprehension: Strategies that work. In Comprehensive Literacy Resource: Grade 3-6 (Chapter 2). Retrieved from: https://www.hand2mind.com/pdf/miriam/ ch2_clr3_6.pdf.

Tseng, S.-S., \& Yeh, H.-C. (2018). Integrating reciprocal teaching in an online environment with an annotation feature to enhance lowachieving students' English reading comprehension. Interactive Learning Environments, 26(6), 789-802. Available at: https://doi.org/10.1080/10494820.2017.1412989.

Vygotsky, L. S. (1978). Mind in society: The development of the higher psychological processes. Cambridge, MA: The Harvard University Press.

Yang, Y.-F. (2010). Developing a reciprocal teaching/learning system for college remedial reading instruction. Computers ङ Education, 55(3), 1193-1201. Available at: https://doi.org/10.1016/j.compedu.2010.05.016.

Yigiter, K., Saricoban, A., \& Gurses, T. (2005). Reading strategies employed by ELT learners at the advanced level. The Reading Matrix, 5(1), $124-137$.

\section{Appendices}

\section{Appendix A}

\section{Reading Comprehension Test}

https://learnenglish.britishcouncil.org/sites/podcasts/files/LearnEnglish-Reading-C1-Giving-and-receivingpositive-feedback.pdf 


\begin{tabular}{|c|c|c|c|c|c|}
\hline RT Strategy & Beginning 1 & Developing 2 & Accomplished 3 & Exemplary 4 & Score \\
\hline Questioning & $\begin{array}{l}\text { Generates simple } \\
\text { recall questions that } \\
\text { can be answered } \\
\text { directly from facts or } \\
\text { information found } \\
\text { within the website's } \\
\text { home page. }\end{array}$ & $\begin{array}{l}\text { Generates main idea } \\
\text { questions that can be } \\
\text { answered based on } \\
\text { information gathered } \\
\text { by accessing one or } \\
\text { more links to the } \\
\text { website's content. }\end{array}$ & $\begin{array}{l}\text { Generates } \\
\text { questions requiring } \\
\text { inference. Facts and } \\
\text { information must } \\
\text { be synthesized from } \\
\text { one or more links } \\
\text { to the website's } \\
\text { content and } \\
\text { combined with } \\
\text { prior knowledge. }\end{array}$ & $\begin{array}{l}\text { Generates questions } \\
\text { flexibly that vary in type, } \\
\text { based on the content read } \\
\text { and the direction of the } \\
\text { dialogue. }\end{array}$ & \\
\hline Clarifying & $\begin{array}{l}\text { Identifies } \\
\text { clarification as a tool } \\
\text { to enhance } \\
\text { understanding and } \\
\text { initiates clarification } \\
\text { dialogue when } \\
\text { appropriate. }\end{array}$ & $\begin{array}{l}\text { Identifies appropriate } \\
\text { words for } \\
\text { clarification with the } \\
\text { dialogue's context. }\end{array}$ & $\begin{array}{l}\text { Assists group in } \\
\text { clarifying identified } \\
\text { words based on } \\
\text { context clues. }\end{array}$ & $\begin{array}{l}\text { Uses strategies for word } \\
\text { clarification that can be } \\
\text { applied generally across } \\
\text { reading contexts. }\end{array}$ & \\
\hline Summarizing & $\begin{array}{l}\text { Summary consists of } \\
\text { loosely related ideas. }\end{array}$ & $\begin{array}{l}\text { Summary consists of } \\
\text { several main ideas } \\
\text { but also many details. }\end{array}$ & $\begin{array}{l}\text { Summary } \\
\text { synthesizes main } \\
\text { ideas, is complete, } \\
\text { accurate } \\
\text { concise. }\end{array}$ & $\begin{array}{l}\text { Summary is accurate, } \\
\text { complete, and concise } \\
\text { incorporating content } \\
\text { vocabulary contained in } \\
\text { the text. }\end{array}$ & \\
\hline Predicting & $\begin{array}{l}\text { Demonstrates } \\
\text { knowledge } \\
\text { predictions as an } \\
\text { active } \\
\text { strategy }\end{array}$ & $\begin{array}{l}\text { Directs } \\
\text { predictions to set a } \\
\text { clear purpose for } \\
\text { reading. }\end{array}$ & $\begin{array}{l}\text { Articulates } \\
\text { predictions that } \\
\text { build logically from } \\
\text { context. }\end{array}$ & $\begin{array}{l}\text { Provides justification for } \\
\text { prediction and initiates } \\
\text { confirmation } \\
\text { redirection based on } \\
\text { information located in } \\
\text { the text. }\end{array}$ & \\
\hline
\end{tabular}

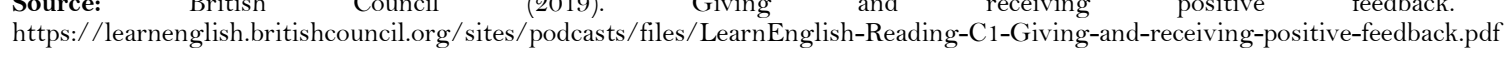

\section{Appendix C}

\section{A semi-structured interview}

1. Can you define Reciprocal Teaching?

2. What is Internet Reciprocal Teaching?

3. What are the different principles of IRT?

4. What are the similarities between RT and IRT?

5. What are the differences between RT and IRT?

6. Did you have any past experience with online learning? If so, how do rate it?

7. How do you think that the sudden move to online learning will affect your performance?

8. Which way do you prefer to read - IRT or printed texts in classrooms? Why?

9. What are the benefits of IRT?

10. What are the challenges you faced when using IRT? 